This item was submitted to Loughborough's Research Repository by the author.

Items in Figshare are protected by copyright, with all rights reserved, unless otherwise indicated.

\title{
Antenna emblems reshaped as icons and esthetic logos (aerial)
}

PLEASE CITE THE PUBLISHED VERSION

http://dx.doi.org/10.1002/mop.27681

\section{PUBLISHER}

(c) Wiley Periodicals, Inc.

\section{VERSION}

AM (Accepted Manuscript)

\section{LICENCE}

CC BY-NC-ND 4.0

\section{REPOSITORY RECORD}

Whittow, W.G.. 2019. "Antenna Emblems Reshaped as Icons and Esthetic Logos (aerial)". figshare. https://hdl.handle.net/2134/12472. 
This item was submitted to Loughborough's Institutional Repository (https://dspace.lboro.ac.uk/) by the author and is made available under the following Creative Commons Licence conditions.

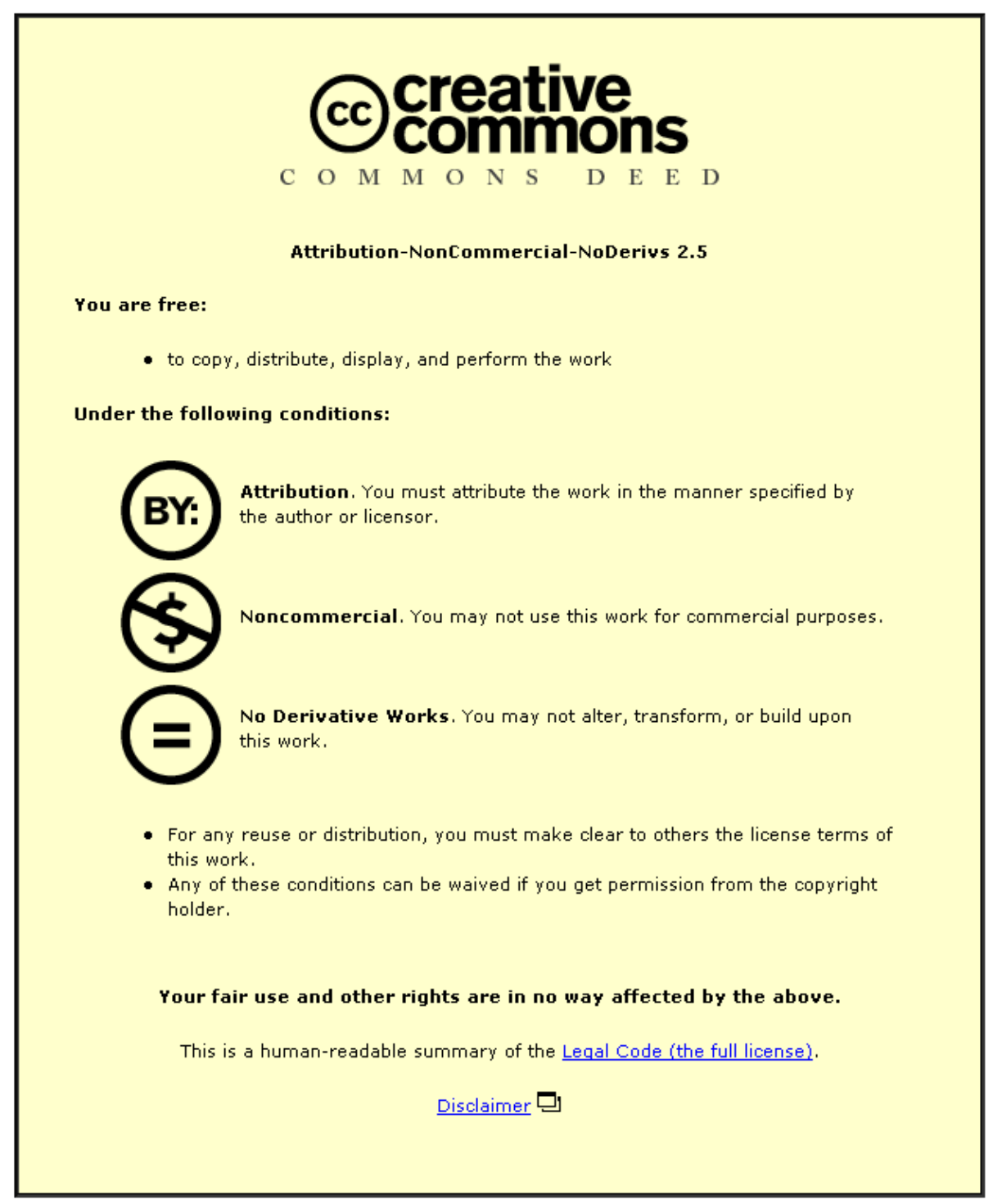

For the full text of this licence, please go to: http://creativecommons.org/licenses/by-nc-nd/2.5/ 
ANTENNA EMBLEMS RESHAPED AS ICONS AND AESTHETIC LOGOS (AERIAL)

\author{
W. G. Whittow \\ School of Electronic, Electrical and Systems Engineering, Loughborough University, \\ Loughborough, Leics. LE11 3TU, United Kingdom \\ Email: w.g.whittow@lboro.ac.uk. \\ Phone: +44 (0)1509 227105. Fax: +44 (0)1509 227014
}

ABSTRACT: This paper introduces the concept of designing microstrip patch antennas to take the form of aesthetic arbitrary shapes or logos. Various intermediate shapes have been examined to analyze the behavior of asymmetric, curved, angular and disconnected sections.

Key Words: Logo, aesthetic design, microstrip patch antenna

\title{
1. INTRODUCTION
}

Antennas and wireless connectivity are essential to our everyday activity. However, antennas are generally functional objects that need to be miniaturised and hidden to avoid hindering the aesthetics of the product in which it is incorporated into. This means compromising the antenna in terms of size which limits the inherent efficiency and bandwidth due to the Wheeler-Chu limits [1]. Surrounding materials and nonideal placement also compromise electromagnetic performance. Conversely, if the antenna was an aesthetic shape, for example a flower, a smiley face or even a company logo, these restrictions would be negated. This concept lends itself particularly to wearable technology where conducting threads can be used to embroider antennas [2]. This new approach to antenna design could be particularly attractive to companies as it reinforces technology and functionality with a recognised brand to create a unique product. The technology itself would also be protected by copyright and registered design rights.

Microstrip patch antennas are popular due to their low profile; ease of construction and the isolation from other objects due to the ground plane [3]. Different geometries have been considered including square, triangular rectangular, circular, elliptical, slots and parasitic elements [4], [5]. However, these shapes were optimised for their electromagnetic performance and the aesthetic aspects were not considered.

Logo-based antennas have recently been considered [6-9]. These were monopole and dipole antennas and hence would be detuned in the presence of nearby metal objects. The original shapes were modified and they required an element of symmetry in the design. In [6], a logo design was placed inside a circle but it was predominantly the circle which acted as the antenna and not the logo. In [7] and [8] the impedance match of a text logo was changed by modifying the shape of connected letters. A text-based dipole RFID antenna has been created by physically connecting individual letters [9]. In a related area, capacitive coupling between distinct structures has been studied [10]. 
Final author version. Paper published in Wiley Microwave and Optical Technology Letters, Volume 55, Issue 8, August 2013, Pages: 1711-1714,

http://onlinelibrary.wiley.com/doi/10.1002/mop.27681/pdf

\section{SIMULATED RESULTS}

Six variations of the Loughborough University (LU) Shield were considered and are shown in Fig. 1. This logo was chosen as it includes asymmetry and disconnected sections - however the design rules can be applied to any number of aesthetic or logo shapes. All the antennas were fed from the left hand side - the feedpoint was moved to obtain the best match for each case. A probe feed was utilised in order to avoid changing the shape of the logo with an added transmission line feed. The patch antennas were placed above a $1.6 \mathrm{~mm}$ thick substrate $\left(\varepsilon_{\mathrm{r}}=4.5\right.$; tan delta $=$ $0.001)$. The ground plane size was $120 \times 120 \mathrm{~mm}$. To allow a fair comparison, the size and aspect ratios of the different patches were fixed at $60 \mathrm{~mm}$ high which meant the width was $50.36 \mathrm{~mm}$.

The logo antennas were simulated using EMPIRE finite-difference time-domain (FDTD) software. The shapes were converted into a single-colour 2D image (jpeg format). Commercial CAD software was then used to convert the image into a $3 D$ STL file with thickness $0.1 \mathrm{~mm}$. Care was taken to mesh the curved structures finely.

(a)

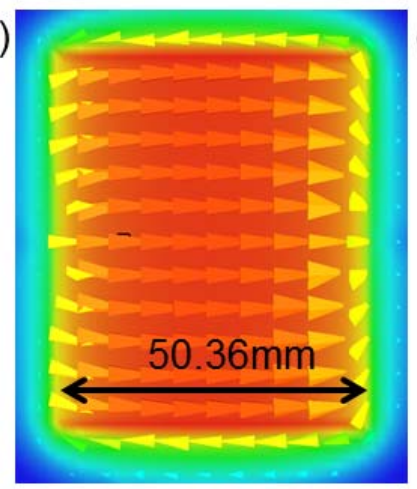

(d)

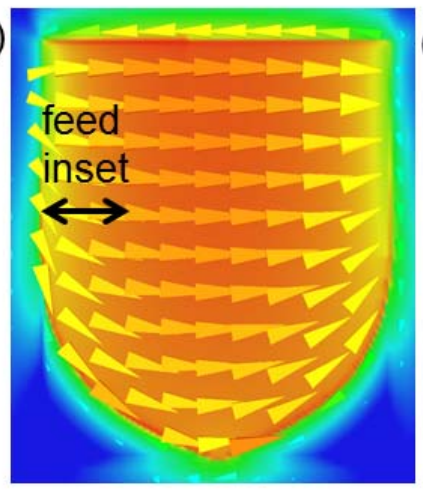

(b)

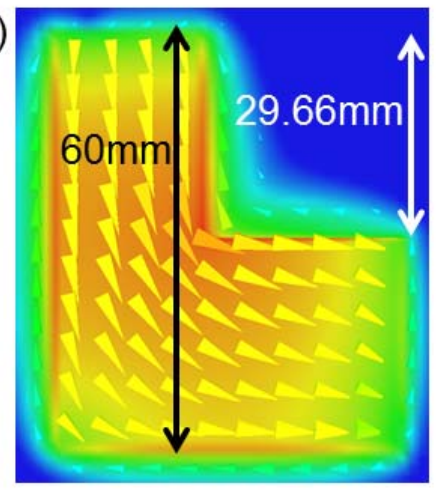

(e)

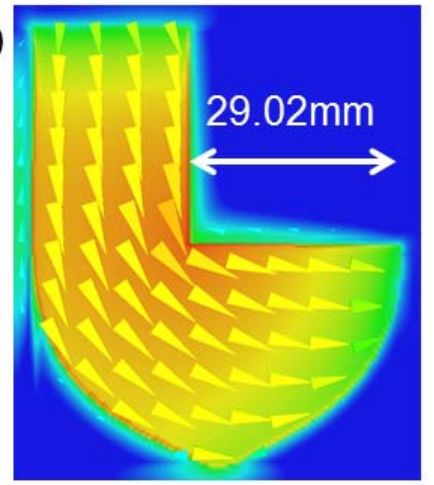

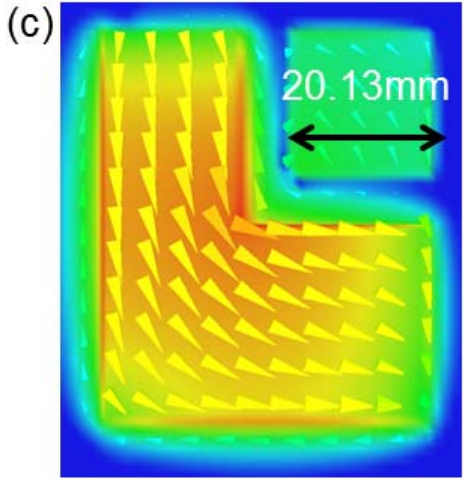

(f)

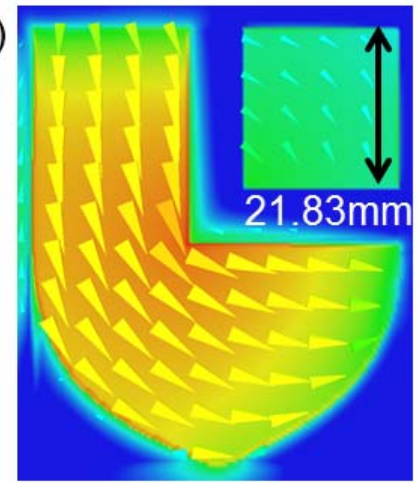

Fig. 1. The geometry of the six patches including the surface currents at the resonance frequency: (a) rectangular; (b) L-shape; (c) L-shape with square; (d) shield; (e) L-shaped shield and (f) LU Shield

The return loss results are shown in Fig. 2. As expected, the antennas could be tuned to a particular frequency by scaling their size. By examining the surface currents and S11 results, the disconnected square had negligible effect at the principal resonance and a marginally larger effect at higher frequencies. However, the square did change the 50 ohm impedance point. 


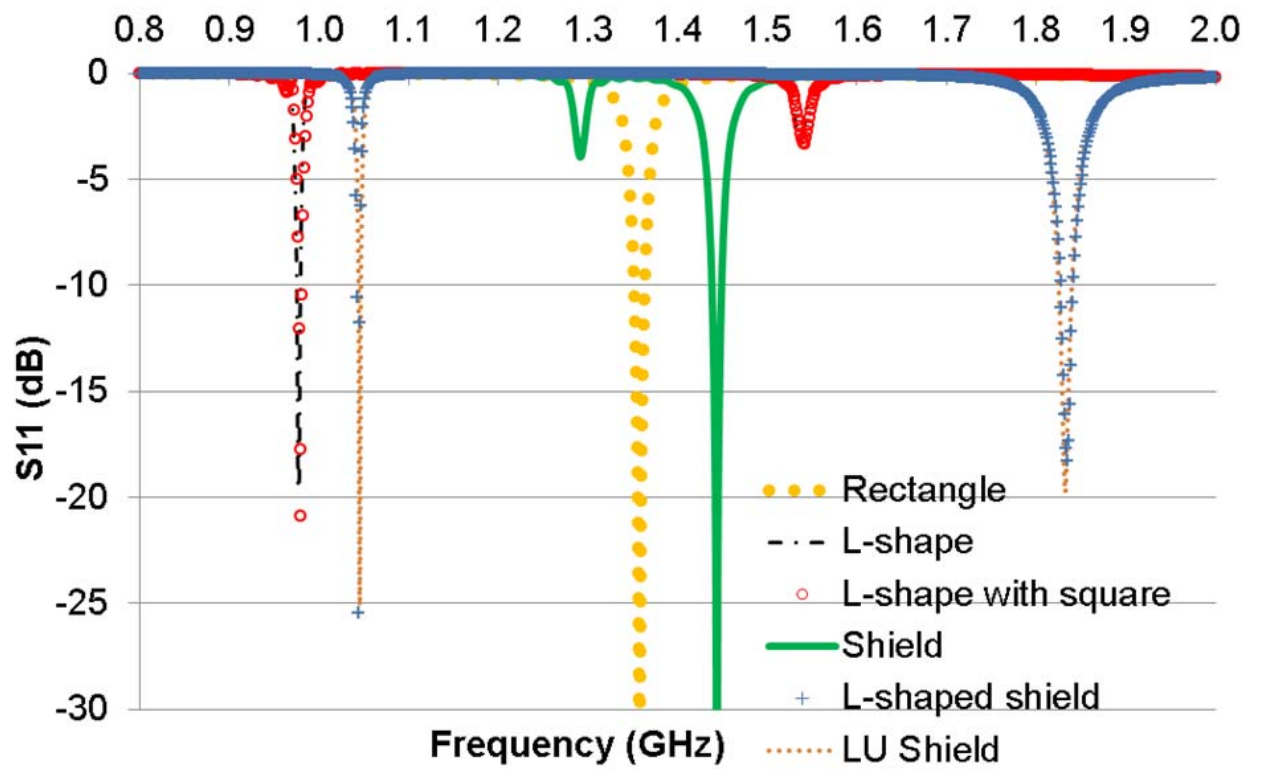

Fig. 2. Simulated return loss of the six patch antennas

The performance of the different antennas is compared in Table 1 . The bandwidth and efficiency could be improved by using a thicker substrate with a lower permittivity. The L-shaped antennas produced longer current paths and hence resonated at a lower frequency (see Fig. 1); consequently the efficiency and fractional bandwidth (FBW) were reduced. Note, comparable efficiency and bandwidth results were obtained for the rectangular patch when a higher permittivity substrate was used to reduce the frequency. The LU Shield had similar performance compared to the angular or curved L-shaped antennas. The second resonance of the LU Shield (at $1836 \mathrm{MHz}$ ) had an efficiency of $85 \%$. The cross and co-polar patterns (not included for space reasons) were slightly tilted due to the asymmetric shape but the overall magnitude is reasonably omnidirectional in the azimuth plane.

Table 1: Simulated performance of the six patch antennas

\begin{tabular}{|l|c|c|c|c|}
\hline $\begin{array}{l}\text { Antenna } \\
\text { geometry }\end{array}$ & $\begin{array}{c}\text { Freq } \\
\mathrm{F}_{0} \\
(\mathrm{MHz})\end{array}$ & $\begin{array}{c}10 \mathrm{~dB} \\
\mathrm{BW} \\
(\mathrm{MHz})\end{array}$ & $\begin{array}{c}\text { Gain } \\
\text { at } \mathrm{F}_{0} \\
(\mathrm{dBi})\end{array}$ & $\begin{array}{c}\text { Eff. } \\
\text { at } \mathrm{F}_{0} \\
(\%)\end{array}$ \\
\hline Rectangle & 1358 & 12 & 5.85 & 80.6 \\
\hline L-shape & 978 & 4 & 2.81 & 46.9 \\
\hline $\begin{array}{l}\text { L-shape } \\
\text { with square }\end{array}$ & 979 & 4 & 2.33 & 42.2 \\
\hline Shield & 1445 & 11 & 6.17 & 86.1 \\
\hline $\begin{array}{l}\text { L-shaped } \\
\text { shield }\end{array}$ & 1044 & 3 & 2.46 & 42.4 \\
\hline LU Shield & 1045 & 4 & 3.41 & 52.6 \\
\hline
\end{tabular}

\section{MEASURED RESULTS}

The LU Shield was etched on an FR4 substrate $\left(\varepsilon_{r}=4.5\right.$; tan delta $\left.=0.02\right)$ as shown in Fig. 3. A hole was drilled through the ground, substrate and patch and the inner pin of an SMA connector was soldered to the top of the patch. The measured results showed excellent agreement with the simulations as shown in Fig. 4. 
Final author version. Paper published in Wiley Microwave and Optical Technology Letters, Volume 55, Issue 8, August 2013, Pages: 1711-1714,

http://onlinelibrary.wiley.com/doi/10.1002/mop.27681/pdf

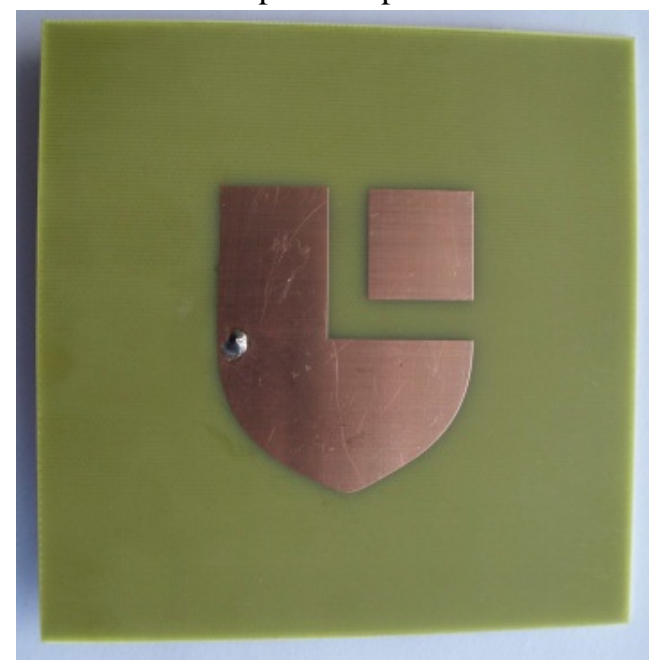

Fig. 3. The fabricated LU Shield antenna on an FR4 substrate

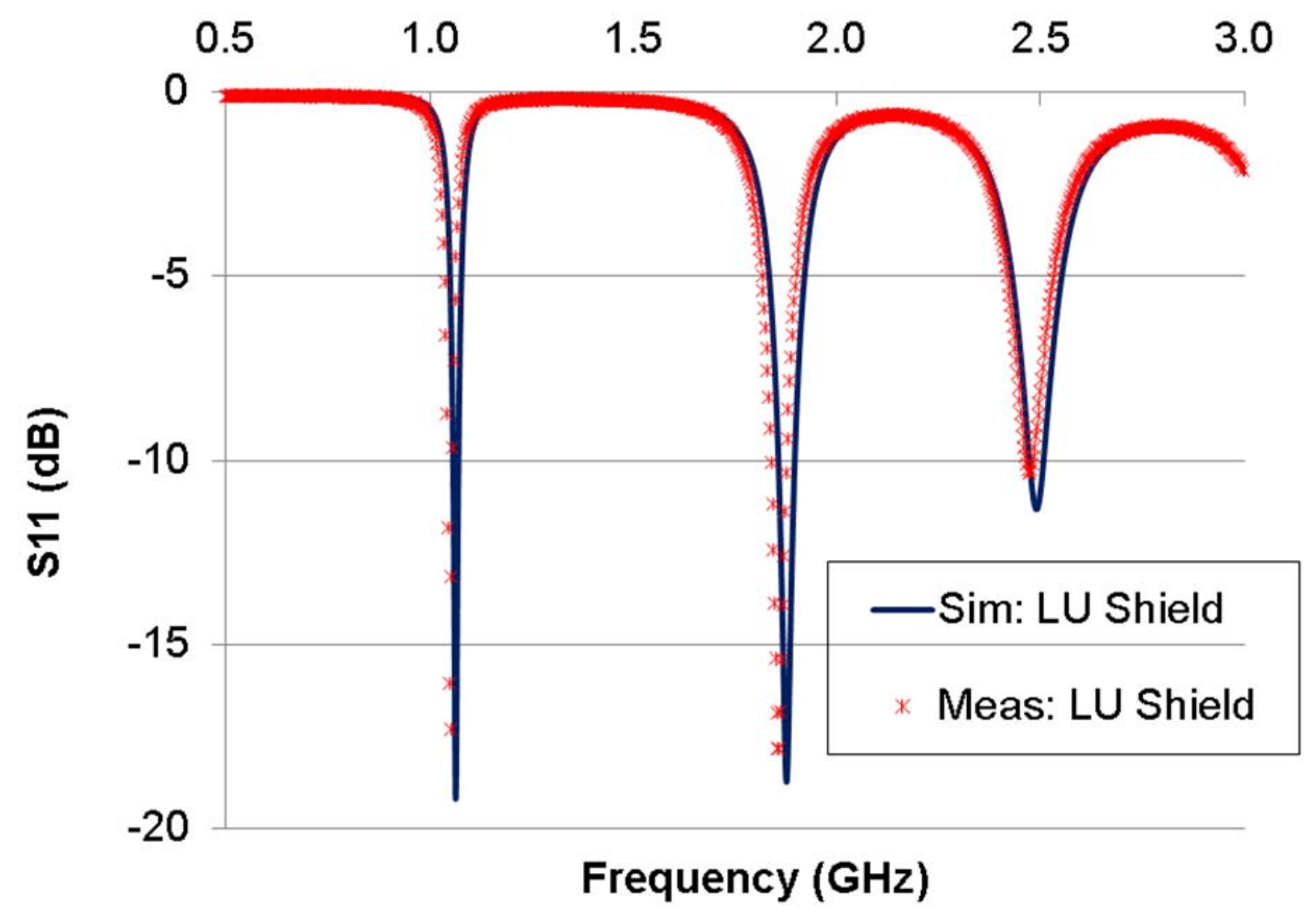

Fig. 4. Simulated and measured return loss of the LU Shield

\section{CONCLUSIONS}

This paper has demonstrated that it is possible to reconsider how we design antennas by giving greater importance to the aesthetic qualities of the design. Although, using a pre-defined shape may not be the optimal antenna design, this can be counteracted by removing the size and cluttered-environmental constraints. Each shape or logo will present different technical challenges but can be analysed using similar principles. 
Final author version. Paper published in Wiley Microwave and Optical Technology Letters, Volume 55, Issue 8, August 2013, Pages: 1711-1714,

http://onlinelibrary.wiley.com/doi/10.1002/mop.27681/pdf

Complex and detailed shapes will lengthen the current path, thereby reducing the frequency. The shapes can then be scaled to the desired frequency. Intricate shapes will exhibit comparable performance to the basic geometric shape. The optimal feedpoint location must be found for each geometry.

A particular challenge is to design antennas when the logo consists of disconnected sections. In certain cases, these parasitic elements could produce wideband or multiband operation. The coupling of discrete shapes will be determined by the direction of current flow, the size of the gap and the frequency. However, in most cases, the coupling will be small and the disconnected section can be made of either metallic or non-metallic materials. Additional simulations related to this paper demonstrated that connecting the disconnected section to the main antenna element with thin strips was possible, but the modified structure did not behave like a continuous patch. Asymmetry in the design introduces a small degree of beam tilt. However, in many situations such as wearable antennas, the presence of the body will result in larger alterations to the radiation patterns.

\section{ACKNOWLEDGEMENTS}

The author would like to thank the Engineering and Physical Sciences Research Council (EPSRC) for funding this work; Dr. Richard Bibb for his assistance creating the STL files; Professor Yiannis Vardaxoglou for valuable discussions on the subject and Loughborough University (who own the copyright) for allowing their Shield to be used in this paper.

\section{REFERENCES}

[1] H. A. Wheeler, "Fundamental Limitations of Small Antennas," Proceedings of the IRE, vol. 35, no. 12, pp. 1479-1484, 1947.

[2] A. Chauraya, S. Zhang, W. G. Whittow, T. Acti, R. Seager, T. Dias, and Y. Vardaxoglou, "Addressing the Challenges of Fabricating Microwave Antennas Using Conductive Threads," in The 6th European Conference on Antennas \& Propagation (EUCAP), 2012.

[3] J. R. James and P. S. Hall, Handbook of Microstrip Antennas. IET, 1989.

[4] K. M. Lee, K. F, Luk, Microstrip patch antennas. Imperial College Press, 2011.

[5] D. Guha and Y. Antar, Microstrip and Printed Antennas: New Trends, Techniques and Applications. Wiley, 2010.

[6] M. S. Mahmud and S. Dey, "Design, performance and implementation of UWB wearable logo textile antenna," in International Symposium on Antenna Technology and Applied Electromagnetics, 2012.

[7] K. Elmahgoub, T. Elsherbeni, F. Yang, A. Z. Elsherbeni, and L. Ukkonen, "Logo-Antenna Based RFID Tags for Advertising Application," ACES Journal, vol. 25, no. 3, pp. 174-181, 2010.

[8] W. C. Weng and C. L. Hung, "Design and optimization of a logo-type antenna for mulitband applications," Progress In Electromagnetics Research, vol. 123, pp. 159-174, 2012.

[9] M. Keskilammi and M. Kivikoski, "Using text as a meander line for RFID transponder antennas," IEEE Antennas and Wireless Propagation Letters, vol. 3, no. 1, pp. 372-374, Dec. 2004.

[10] W. G. Whittow, "Capacitive coupling of discrete micro-sized gaps for RF applications," IET Microwaves, Antennas \& Propagation, vol. 6, no. 13, pp. 1481-1486, 2012. 